\title{
Entrevista com Peter Low ${ }^{1}$
}

\author{
Lauro Meller e Daniel Padilha Pacheco da Costa*
}

Peter Low é membro sênior na Universidade de Canterbury em Christchurch (Nova Zelândia), e suas áreas de pesquisa são Teoria da Tradução e Poesia e Canção Francesas. Tanto como tradutor quanto como pesquisador, ele é um dos principais especialistas em tradução de canções. Ao se deparar com o desafio de produzir traduções cantáveis, e baseado em sua própria experiência como professor de francês na Universidade de Canterbury e como pianista com formação clássica, ele elaborou um método original, o Princípio do Pentatlo.

Em seu livro, Translating Song: lyrics and texts ${ }^{2}$ (2017), Peter Low tende a defender a noção de que letras de canção geralmente devem ser traduzidas de modo a serem cantadas sobre a melodia original - aquilo que ele chama de "tradução cantável". Embora isso soe quase impossível, milhares de canções são traduzidas, no mundo inteiro, e muitas delas são tão bem traduzidas que os ouvintes nem chegam a suspeitar que eram originalmente cantadas em outra língua. O que se segue é a entrevista que realizamos com Peter Low. ${ }^{3}$

\footnotetext{
${ }^{1}$ E-mail: peteralanlow@gmail.com.

${ }^{*}$ Universidade Federal do Rio de Grande do Norte (UFRN) e Universidade Federal de Uberlândia (UFU).

${ }^{2}$ Traduzindo canções: letras e textos (inédito em português).

${ }^{3}$ Esta entrevista é o resultado de três diferentes fases. Ela começou em outubro de 2019, quando Lauro Meller viajou para Christchurch-NZ, a fim de passar duas semanas trabalhando com Peter Low. Após o aceite de Low em ser entrevistado para o segundo número especial de Tradução em Revista sobre Tradução \& Música, Daniel P. P. da Costa enviou a Peter Low perguntas complementares, que foram respondidas por e-mail durante os meses de julho e agosto de 2020. Finalmente, Lauro Meller e Daniel P. P. da Costa entrevistaram Peter Low conjuntamente, por videoconferência, em 5 de agosto de 2020.
} 
Lauro Meller (LM): Professor Low, conte-nos, por favor, um pouco sobre sua formação acadêmica e como o senhor se envolveu com os Estudos da Tradução.

Peter Low (PL): Após estudar na Nova Zelândia e na França, eu consegui um emprego na universidade para ensinar língua e literatura francesas. Um escritor sobre cujos trabalhos eu lecionei foi Prévert, e para mim seus poemas e textos populares pareciam demandar uma tradução em um inglês natural, então eu trabalhei nisso. Mais tarde, percebi uma necessidade de ensinar aos alunos a abordarem a tradução como uma habilidade específica (um ofício e, às vezes, uma arte). Então, desenvolvi um curso em tradução francêsinglês. Eu também li muito sobre Teoria da Tradução, o que mais tarde me possibilitou ensinar a alunos que trabalhavam com outras línguas. Existem princípios gerais, e acima de tudo existem perguntas gerais sobre as quais um tradutor deve refletir.

LM: Além de ser uma referência nos Estudos da Tradução, em particular na tradução de canções, o senhor também trabalhou como tradutor. Poderia nos contar um pouco sobre as canções ou os gêneros que traduziu?

PL: Eu tinha um cargo universitário; então, traduzir era uma atividade complementar, e eu raramente era pago por isso. Eu geralmente traduzia textos não-literários, cheguei a traduzir até mesmo um livro sobre urânio empobrecido. Eu nunca fui intérprete nem fiz legendagem, quase nunca. Mas surtitling sim, eu forneci as legendas para várias óperas francesas e italianas. A poesia não me assustava (talvez ela devesse ter-me assustado!). Recentemente, colaborei em traduções do poeta Évariste de Parny ${ }^{4}$. Geralmente, eu fazia o que se chama de traduções-recitais: versões nãocantáveis de poemas franceses e letras de canções que seriam impressas em programas de concerto ou em encartes de CDs, onde a canção é cantada no original. Mas esse é um gênero diferente - certamente, possui um skopos diferente - das "traduções cantáveis", que são destinadas a uma

\footnotetext{
${ }^{4}$ Cf. Parny (2018).
} 
performance na língua-alvo. Eu acho que foram os meus vários artigos sobre tradução de canções que motivaram o convite que recebi para escrever um livro sobre o assunto.

Daniel P. P. da Costa (DC): O senhor comentou que traduziu poesia antes de começar a traduzir canções. Muitos dos problemas discutidos na tradução literária são comuns à tradução de canções. Quais são as diferenças entre a tradução literária e a tradução de canções?

PL: Traduz-se um poema para a página impressa e, às vezes, para ser recitado. Mas uma letra de canção é um componente de uma forma de arte híbrida chamada canção. Esse skopos determina uma maior importância dada aos sons e aos ritmos, e uma necessidade absoluta de cantabilidade.

DC: O senhor forneceu legendas para seis óperas francesas e italianas. Também escreveu sobre elaborar legendas para óperas, tanto em artigos ${ }^{5}$ como no capítulo "Traduções para serem lidas" de seu livro". Quais são as principais dificuldades dessa tarefa específica?

PL: As questões habituais, que envolvem significado e naturalidade, somadas a uma preocupação com a boa comunicação em uma situação com skopos específico - mas menos dificuldades do que com as traduções cantáveis.

DC: Desde o início do Romantismo até agora, as óperas traduzidas vêm sofrendo uma constante desvalorização no Brasil, apesar de alguns defensores de peso, como o escritor e musicólogo modernista Mário de Andrade $^{7}$. Apesar disso, as óperas italianas são com frequência cantadas em tradução não apenas no Brasil, mas também na Alemanha, na França e em países anglófonos. "Atualmente, entretanto", como o senhor afirma em seu livro, "a maioria das traduções para óperas não são feitas para cantar,

\footnotetext{
${ }^{5}$ Cf. Low (2002).

${ }^{6}$ Cf. Low (2017, p. 40-62).

${ }^{7}$ Cf. Kaiser (1999).
} 
mas para serem lidas em telas como legendas" (LOW, 2017, p. 7, tradução minha). Por que as óperas traduzidas não são executadas com mais frequência? Seria esta a razão para a sua teoria não lidar muito com traduções cantáveis de óperas ou de musicais? Você poderia estabelecer as principais diferenças entre traduções cantáveis de óperas e de musicais e traduções cantáveis de canções?

PL: Os italianos inventaram a ópera, e a língua deles, com poucas vogais e poucas sílabas fechadas, é maravilhosa para o canto. A decisão de usar traduções depende principalmente dos diretores, que, em geral, entendem as palavras em italiano. Mas há um bom argumento para que se apresente a história em uma língua na qual a plateia consiga acompanhar. Para mim, a melhor discussão sobre a tradução de óperas está no livro Translating for Singing, de Apter e Herman ${ }^{8}$. Mas o meu livro apresenta um bom argumento: “Nas óperas e nos musicais, toda canção precisa ser coerente com a performance cênica global à qual ela pertence, necessidade essa que não é atendida pelos meus cinco critérios" (LOW, 2017, p. 110, tradução minha). O texto-alvo deve desempenhar o papel esperado dentro de um enredo complexo, e dentro do mundo ficcional do personagem. Essas considerações tendem a levar a mais concessões e a uma maior flexibilidade com o sentido literal.

DC: Eu gostaria de lhe perguntar sobre os critérios para a escolha do textofonte em uma tradução de canção. Muitos intérpretes (por exemplo, Ella Fitzgerald) improvisam de muitas formas, inclusive com a letra das canções, modificando-as ou adicionando estrofes. Muitas vezes, há mudanças significativas entre uma performance e outra nas várias gravações de standards do jazz norte-americano. Observamos o mesmo fenômeno na música brasileira. $O$ compositor Noel Rosa é um exemplo disso: dependendo da gravação, a letra pode variar substancialmente. Como o senhor elege a letra original a ser utilizada em uma tradução? Que

${ }^{8}$ Cf. Apter e Herman (2016). 
critérios o senhor utiliza para determinar o texto-fonte das canções que o senhor traduz?

PL: De modo geral, eu escolho um texto publicado, presumivelmente autorizado pelo compositor. Mas quando há várias versões gravadas, os tradutores podem seguir suas próprias preferências.

LM: Em uma passagem de seu livro, o senhor se indaga se as canções devem ser apresentadas na língua do público ou não. Para lhe dar um exemplo brasileiro, o cantor e compositor Caetano Veloso lançou muitas canções - até mesmo álbuns inteiros - cantando em línguas que não o português: inglês, espanhol, italiano, francês. Quem o senhor supõe que seria o público presumido dessas gravações?

PL: Minha opinião é a de que, se uma canção for executada na língua do público, os ouvintes e os cantores terão uma experiência diferente. Se eu ouço uma canção em russo, eu posso apreciá-la por causa da melodia romântica de Tchaikovsky - mas perco toda uma dimensão verbal, então essa melodia poderia ser executada por um violino. Meu livro não afirma que canções devem ser sempre executadas em tradução, mas ele refuta o contrário - que é a suposição de que toda canção deva ser cantada em sua língua original, quer a plateia a entenda ou não - esta é a abordagem que, às vezes, parece prevalecer. Eu sei que alguns dos maiores compositores de óperas queriam utilizar a língua do público. Puccini afirmou que queria suas óperas cantadas em francês em Paris. Wagner queria suas óperas em francês, quando apresentadas em Paris. Se você escuta vozes em uma língua estrangeira, você está perdendo parte do sentido do trabalho, a dimensão verbal.

DC: No final do segundo capítulo de seu livro, o senhor afirma: "É provável que algumas canções - uma pequena minoria - sejam impossíveis de serem bem traduzidas, por razões que são linguísticas, culturais ou ambas as coisas" (LOW, 2017, p. 38, tradução minha). O senhor 
já abandonou uma tradução de canção por causa de sua "intraduzibilidade"? Em sua experiência, o senhor considera que algumas canções não deveriam ser traduzidas, mas deixadas no original?

PL: Certa vez, eu desisti de uma canção de Brassens. Eu até menciono uma canção de Perret como sendo intraduzível. Alguns textos estão muito envolvidos na língua-fonte e em sua cultura. Alguns são tão primorosos que não deveriam ser mexidos. E também existem textos que são verbalmente fracos, e que não merecem atenção.

LM: Quando o senhor menciona canções que "não merecem atenção", seria isso o oposto de "canções com poder de permanência", nas palavras de Malcolm McNeill [cantor de jazz em Christchurch]?

PL: Malcolm gravava canções de Hoagy Carmichael porque achava que essas canções tinham poder de permanência no tempo, ou seja, elas poderiam ser boas canções em diferentes épocas, em diferentes culturas, enquanto que algumas canções pop que se escuta são bastante descartáveis - elas só serão populares por pouco tempo e, então, desaparecerão. Eu acho que "poder de permanência" implica uma qualidade e um mérito que irão conferir durabilidade a uma canção. Não seria esse o caso de uma canção política das últimas eleições, porque ela não teria poder de permanência. Você sabe, tanto quanto eu, que produzir uma boa tradução cantável envolve um trabalho árduo. Por isso, não vai querer desperdiçar seu tempo em algo que será facilmente esquecido.

LM: Não estamos aqui falando do cânone? Embora isso soe impressionista, no fim das contas existem boas canções e más canções, não é verdade?

PL: Claro que sim! Subjetivamente, eu posso afirmar que "Summertime" é uma boa canção porque eu gosto dela; eu também posso dizer, objetivamente, que centenas de pessoas também acham que "Summertime" é uma boa canção. Ela foi regravada dezenas de vezes, ela gruda na memória 
das pessoas e, quando, você desce a rua e a cantarola [entoa a melodia de "Summertime"], as pessoas a reconhecem. Existe evidência objetiva. Você não precisa analisar as estranhas harmonias que Gershwin usa, nem precisa conhecer a ópera Porgy and Bess, de onde aquela melodia saiu; a canção provou ter uma espécie de qualidade, de mérito, goste você dela ou não.

LM: Mas também existem "más canções" - e com isso quero dizer, sem profundidade ou originalidade - que, no entanto, vendem milhões de cópias e também grudam na memória das pessoas ao longo do tempo. Essas também não poderiam ser consideradas "canções com poder de permanência"?

PL: Para mim, "poder de permanência" significa algo além do fato de que ela se tornou conhecida. Existe uma canção de Natal chamada "The little drummer boy", que eu considero péssima. Ela foi gravada e você pode ouvila em shopping centers e lugares assim. Eu tenho a prerrogativa de rejeitá-la do meu cânone de boas canções, mas não posso negar que ela seja famosa. Por outro lado, existem obras da música europeia antiga que eu considero maravilhosas - obras como "Amarilli, mia Bella", que quase ninguém conhece, mas que é uma belíssima canção italiana do final do século XVI. É assim que as coisas são. A popularidade parece chamar popularidade, mas quanto ao poder de permanência - e aqui eu uso uma outra frase de meu amigo Malcolm: uma boa canção é "uma canção que me alimenta". Uma bela canção de Schubert, ou Fauré, ou - sei lá - um compositor italiano. Se eu me sinto alimentado por ela, em meu coração, em minha mente ou em ambos, então essa é uma boa canção.

DC: $O$ senhor mencionou a ópera Porgy and Bess ${ }^{10}$, na qual as variantes dialetais dos personagens desempenham um importante papel em denotar as divisões raciais e de classe. No segundo capítulo de seu livro, ao discutir “Problemas da língua não-padrão (dialeto, socioleto, gíria,

\footnotetext{
9 “Amarilli, mia Bella” (1601), música de Giulio Caccini e letra de Giovanni Battista Guarini.

10 Porgy and Bess (1935), música de George Gershwin e letra de Ira Gershwin e DuBose Heyward.
} 
coloquialismos)" (LOW, 2017, p. 28, tradução minha), o senhor cita um exemplo conhecido do uso de inglês não-padrão nessa ópera: "I loves you" [Eu ama você]. Como regra geral, o senhor aplica às canções o conselho de Newmark de "processar apenas uma pequena proporção das palavras dialetais da língua-fonte" (NEWMARK, 1988, p. 95, tradução minha). Mesmo seguindo esse "princípio de moderação" na tradução de língua não-padrão em canções, existem casos em que esse problema deva ser deixado de lado em favor de outras questões?

PL: Palavras não-padrão não são incomuns em canções, e um texto-alvo geralmente consegue lidar com isso. Mas muitas vezes elas não têm muita importância, e o tradutor pode ignorá-las. Mas aqui (tanto quanto em outros lugares), nós precisamos nos perguntar: “Essa é uma marca significativa desse texto-fonte em particular, que deva ser replicada para que haja uma tradução verdadeira?" Quando Bob Dylan canta "a-changing" em vez de "changing", eu não replicaria isso em outra língua, caso isso me desviasse do objetivo de traduzir a mensagem nuclear da canção.

LM: O Princípio do Pentatlo define cinco critérios para a tradução de canções. Como o senhor chegou a essa metáfora? Qual foi a sua inspiração?

PL: Muitas canções clássicas (tais como os Lieder alemães) são impressas com as chamadas "versões cantáveis em inglês". Mas a maioria delas é medíocre ou ruim, e raramente são usadas pelos cantores. Algumas pessoas se opõem, por princípio, às traduções cantáveis. Eu sentia que conseguia identificar grandes problemas estratégicos na abordagem dos tradutores - eles falhavam ao não considerarem, de maneira apropriada, todos os critérios relevantes, que geralmente são cinco. Ao desenvolver minha própria abordagem, principalmente para me aprimorar, eu considerei palavras como "malabarismo" e "compensações", antes de me deparar com a metáfora do "pentatlo", que tem a virtude de sugerir um "escore geral para os cinco critérios". ${ }^{11}$

11 Ao utilizar essa metáfora esportiva, Low dá a entender que, da mesma forma como um atleta não conseguiria um escore máximo nos cinco eventos do Pentatlo, nenhuma tradução será $100 \%$ perfeita. 
LM: "Cantabilidade" é, em suas próprias palavras, "relativa facilidade de vocalização", e o senhor acrescenta que ela deve ser "[...] o primeiro critério, pois qualquer texto-alvo que tenha um resultado pobre nesse quesito será um fracasso, e não deverá ser cantado, nem mesmo pronunciado, quaisquer que sejam suas outras virtudes" (LOW, 2017, p. 82, tradução minha). Por "primeiro critério" o senhor quer dizer "prioridade número um" em comparação com os outros quatro critérios do pentatlo?

PL: Não número um em importância, mas um sine qua non; trata-se de um critério que tem de ser atendido em um nível adequado, pois, do contrário, você estará perdendo seu tempo. Se a peça não puder ser executada por causa de problemas de vocalização, porque uma tradução em polonês contém a palavra tal e tal que não pode ser cantada, ainda que seja falada em polonês - as línguas eslavas parecem ser piores que as outras -, então você deverá revisar sua tradução para que ela possa ser cantada.

LM: Ainda de acordo com o senhor, as melhores pessoas para avaliar a cantabilidade não são os tradutores, mas os próprios cantores.

PL: Cantores, ou professores de canto, ou regentes de coral - pessoas que realmente entendem do assunto. Uma vez, uma cantora famosa abordou um tradutor, dizendo: "Eu quero uma vogal diferente para aquela nota alta você pode me dar uma vogal diferente?" Aquela parecia uma escolha totalmente razoável para o tradutor, e poderia haver razões para que ele não cedesse, mas ela sabia o que conseguia cantar bem. Algumas línguas têm vogais maravilhosas: o italiano é muito bom, o Maori é muito bom, o inglês tem vogais difíceis para notas agudas, palavras que não devem ser cantadas em notas altas, palavras como "the", que nunca deve receber ênfase, pois é sempre átona, e talvez seja a palavra mais comum na língua. $\mathrm{O}$ inglês tem

Sendo assim, algumas concessões precisam ser feitas, de acordo com as dificuldades e características de cada canção: algumas delas irão se amparar mais fortemente no aspecto rítmico, outras nas rimas, etc. 
muitos ditongos - uma palavra como "today", com o ditongo /ei/ - não são más vogais -, mas podem criar problemas no canto. Outras línguas, como o italiano, têm vogais muito puras, que você pode cantar sustentando - além disso, aquela sílaba geralmente não vai ter uma consoante no fim, e isso pode criar problemas, talvez mais em inglês do que em português.

LM: Então, os tradutores de canções deveriam começar com o critério da cantabilidade em mente? Eu acredito que alguns tradutores podem dar uma importância suplementar ao ritmo nos primeiros estágios da tradução (isto é, manter o mesmo número de sílabas e as mesmas tônicas tanto no texto-fonte como no texto-alvo), a fim de garantir que o novo texto possa ser cantado sobre a melodia original.

PL: Eu diria que a cantabilidade deve ser o primeiro critério para avaliar uma tradução de canção. Não é a primeira coisa a ser trabalhada. Na realidade, eu desenvolvi esses cinco critérios à medida que eu estava fazendo um trabalho de tradução cantável. Foi apenas após isso que eu considerei que eles poderiam ser usados para avaliar e comparar as traduções entre si. De fato, escrevi um artigo ${ }^{12}$ no qual eu comparava três tradutores de canções de Schubert - eu tentei avaliar quão bem eles tinham conseguido trabalhar com o meu pentatlo - e é claro que alguns se saíram melhor, e outros tiveram um resultado mais fraco. A razão por que eu a coloco em primeiro lugar na avaliação é que, se a cantabilidade for pobre, então você está perdendo seu tempo. É isso.

DC: Muitas traduções de canções e de óperas cantadas em tradução não respeitam de forma estrita os padrões rítmicos do texto-fonte e, mesmo assim, são cantáveis. Quão rigoroso deve ser o tradutor de canções e de óperas com relação a isso?

PL: Para mim, o ritmo de qualquer verso traduzido pode ser medido facilmente (embora de forma grosseira): se as tônicas caírem bem na língua-

${ }^{12}$ Cf. Low (2008). 
alvo e as sílabas combinarem com o a língua-fonte, então eu diria que o ritmo está $100 \%$. Mas, em geral, eu acho que um pouco de flexibilidade na contagem de sílabas me permite atingir um resultado geral mais satisfatório.

\section{LM: O senhor menciona que as rimas são “[...] o critério mais fácil de se avaliar, e geralmente o menos importante" (LOW, 2017, p. 80, tradução minha). As rimas são de fato tão secundárias?}

PL: Eu concordo que, às vezes, elas são muito importantes, mas não se pode dizer que "este compositor sempre dá muita importância às rimas", pois qualquer bom compositor será versátil, e alguns podem até fazer canções sem rimas, ou usá-las com parcimônia. Um de meus compositores favoritos, Tom Lehrer, faz um trabalho brilhante com as rimas. Ele é um judeu americano de Nova Iorque que escreveu somente umas vinte canções, mas todas elas são canções satíricas que se tornaram clássicos. Eu queria incluir uma delas em meu livro, mas não conseguia ter acesso a ele ou a seus agentes, era impossível, e então alguém disse: "Isso é humor negro, e parte do seu público pode não gostar". Aqui está o começo: "I hold your hand in mine, dear / I press it to my lips / I take a healthy bite / From your dainty fingertips. [...]". ${ }^{13}$ Claro que é humorístico, mas como você traduziria isso? Ele também tem uma canção maravilhosa em que ele tinha mais ou menos doze rimas que terminavam em "-ality" - e também uma sobre a Tabela Periódica, que é uma maravilhosa letra alternativa ${ }^{14}$. Simplesmente, não se pode traduzi-la sem as rimas, pois a graça está justamente nelas. Não existe uma fórmula padrão para se traduzir uma canção, você precisa analisar de perto a canção em questão. De qualquer maneira, o que quero dizer é que, às vezes, a rima confere à canção um gusto, uma energia, e se você perder isso,

\footnotetext{
${ }^{13}$ A letra exata da canção é a seguinte: “Eu seguro sua mão na minha, querida / Eu a pressiono contra meus lábios / Dou uma mordida gostosa / Nas saborosas pontas dos seus dedos / Minha alegria seria completa, querida / Se você ao menos estivesse aqui / Mas eu ainda guardo a sua mão / Como uma preciosa lembrança / Na noite em que você morreu eu a cortei fora / Eu nem mesmo sei por quê / Pois agora, cada vez que eu a beijo / Fico com manchas de sangue na gravata / Desculpe-me, agora que a matei / Pois nosso amor era algo especial / E até que eles venham me buscar / Estarei segurando sua mão na minha" (Tradução literal minha, não cantável sobre a melodia original). Disponível em: https://genius.com/Tom-lehrer-i-hold-your-hand-in-mine-lyrics. Acesso em: 06 out. 2020.

${ }^{14}$ Optei por traduzir por "letra alternativa" o conceito de replacement text (cf. Low, 2017, p. 117-118).
} 
perderá o efeito conclusivo de uma rima ao final de uma estrofe, isto é, o verso final em um grupo de quatro ou seis, quando entra o interlúdio instrumental - um efeito como se você estivesse fechando a porta e ouvisse um clique -, e a rima provoca esse efeito em um verso. Então, esse é um valor estrutural, ele diz a você onde fica o final de uma seção em uma canção. E também, provavelmente, no final de uma sentença, é uma questão gramatical. Mas está claro para mim que há muita música vocal sem rimas, e isso varia de cultura para cultura: a música Maori não tem rimas, e as canções em Latim, as canções de igreja, geralmente não trazem rimas.

LM: Em contraste com os exemplos que o senhor acabou de mencionar, eu diria que as rimas ainda são relativamente importantes na Música Popular Brasileira. Podemos então concluir que a importância das rimas varia de língua para língua?

PL: Isso é interessante - existe uma expectativa cultural, no português brasileiro, assim como, na verdade, existe também no inglês, de que as canções populares tenham rimas. Não se espera mais, em inglês, que a poesia rime, mas no passado, isto é, há 200 anos, as pessoas diriam: “Isso não é um poema, não rima"; e os poetas tinham esse status provavelmente porque eles sabiam rimar. Em francês, as rimas são especialmente importantes porque elas fornecem um pouco do ritmo de um poema ou canção. Elas não são tão importantes em inglês, e você pode falar pelo português. Eu pergunto coisas como: “O meu texto-alvo deve rimar? A rima é essencial?" E existem vários motivos pelos quais ele deveria. As rimas tornam a canção mais memorável, mais eufônica, talvez mais contundente. Eu acho que muitas canções espirituosas são como as de Tom Lehrer - ele é, em parte, motivado pelas rimas, e se você não rimar pelo menos a metade na sua versão, ela vai perder esse vigor. Bem, isso significa, evidentemente, que você está fazendo uma escolha pelas rimas, em detrimento do sentido - e é disso que trata esse capítulo. ${ }^{15}$ Defendo, na página 104, a tradução de uma canção de

${ }^{15}$ Cf. o capítulo 6 - “Singable translations (B) - rhythm and rhyme", em Translating Song (LOW, 2017, p. 95-113). 
Shakespeare feita por Schubert, porque a palavra "Kindheit" não significa "kindness [bondade]", significa "childhood [infância]" - mas rima perfeitamente e se encaixa bem, na minha opinião, embora pareça ser um erro. Além dessas questões, eu acho mais importante optar por uma margem de flexibilidade - as rimas não terão de ser em igual número, ou tão perfeitas quanto na fonte. As rimas originais podem não ser observadas. Se houver, digamos, dezoito palavras francesas rimando com "amour", isso é algo para os virtuosos; eu não conseguiria fazer isso em inglês - talvez se possa fazer isso em algumas línguas - mas eu tentarei manter as rimas, e se eu acabar com metade dos versos sem rimar, talvez isso não importe tanto, desde que as rimas-chave, em posições finais, nos proporcionem o mesmo efeito.

\section{LM: Acerca das diferenças entre traduções, adaptações e letras alternativas ${ }^{16}$, o senhor defende a posição de que estas duas últimas não deveriam ser tratadas pelos Estudos da Tradução.}

PL: Sim. Com relação ao sentido, e embora eu seja um adepto do paradigma da fidelidade, concordo que algumas licenças podem ser tomadas em favor de algum outro aspecto mais importante - mas não a ponto de as traduções se tornarem adaptações (isso sem falar nas letras alternativas - que, embora sejam um fenômeno cultural legítimo, não se situam dentro do escopo dos Estudos da Tradução). Certa vez, participei de um debate com alguns acadêmicos na Grã-Bretanha sobre isso. Eu disse: "Não existe nenhuma tradução aqui, então isso não é um objeto adequado aos Estudos da Tradução". Não estou negando a importância cultural das letras alternativas - e, de fato, uma boa canção, como "Lili Marlene", foi substituída por muitas letras alternativas. $\mathrm{Na}$ verdade, tenho certeza de que os soldados neozelandeses que marcharam durante a Guerra estavam cantando uma letra alternativa da melodia de "Lili Marlene" - não era uma tradução, mas uma canção anti-germânica vulgar.

\footnotetext{
${ }^{16}$ Cf. o capítulo 7 - “The place of adaptations", em Translating Song (LOW, 2017, p. 114-127).
} 
LM: Alguns autores distinguem traduções de adaptações em termos de porcentagens - textos com uma alta porcentagem de fidelidade de sentido entre a língua-fonte e a língua-alvo se classificariam como traduções, e aqueles que tomam muitas liberdades, adaptações. Qual sua visão sobre isso?

PL: Eu não adoto essa abordagem. Minha abordagem é a seguinte: “Se todos os detalhes significativos tiverem sido transferidos, trata-se de uma tradução" (LOW, 2017, p. 116, tradução minha) - e a palavra significativa, claro, isso é uma questão de opinião. Mas para dizer que isso não é uma tradução, eu teria de dizer: "Essa referência à morte da mãe dela foi omitida, e esse é um ponto significativo, então isto é um arranjo, uma adaptação". Nessa definição de adaptação, eu disse que "alguns detalhes significativos não foram transferidos", com a cláusula suplementar, "os quais poderiam ter sido facilmente transferidos". Vou tomar um exemplo da famosa canção de Jacques Brel, "Ne me quitte pas". Para mim, é significativo o fato de ser um imperativo - "Não me abandona". E quando o tradutor americano a traduziu como "If you go away [Se você for embora]", houve uma parte significativa do enunciado que se perdeu. Ele se tornou uma condicional supunha-se que a mulher estava pensando em partir, mas não tinha partido ainda. Porém, para provar que esta é meramente uma adaptação, eu preciso afirmar que ela poderia ter facilmente começado com “Don't walk out on me [Não vai embora]”, “Don't leave me [Não me deixa]”, “Don't abandon me [Não me abandona]". Isso poderia ter sido feito sem qualquer dificuldade, então a outra versão contém um desvio não-obrigatório, um adendo ou modificação. Ela se tornou uma canção de sucesso em inglês, mas o teste decisivo seria comparar, de fato, as palavras. A adaptação deliberadamente modificou o texto-fonte, e a tradução não fez isso. Ele poderia, de modo relutante ou acidental, tê-la modificado, é claro. Eu não estou afirmando coisas do tipo "ah, a ordem das palavras mudou!" - claro que a ordem das palavras mudou, é outra língua!

Não estou dizendo coisas como: "Veja, o texto-fonte tem três palavras começando com a letra ' $z$ ', e no texto-alvo só tem uma" - ora, espere um pouco: essas três palavras começando com ' $z$ ' são realmente significativas no 
texto-fonte? Provavelmente não são. Dou um exemplo na próxima página ${ }^{17}$, que é "Frère Jacques". Tem uma letra alternativa ao final da página que diz assim [ele canta a melodia de "Frère Jacques"]: "In the forest / In the forest / There are trees / There are trees / Johnny saw a squirrel / Johnny saw a squirrel / And some bees / And some bees" ${ }^{18}$ Isso não é uma tradução, é uma letra alternativa! Eu tomo algumas liberdades com detalhes insignificantes nas minhas versões, e ainda assim eu as chamo de traduções. E se se quiser provar que fiz uma má tradução, você terá de demonstrar que ela poderia ser facilmente melhorada. Isso é pragmático. Mas aqui não estamos trabalhando com perfeição.

E um aspecto com o qual eu realmente não concordo é quando uma canção solo é criada como veículo para que então o intérprete agregue valor a ela, de modo a vendê-la a um público. Claro, algumas más canções vendem tão bem pelas mãos de um bom intérprete que elas se tornam famosas. Mas se você tem uma canção cujo cantor não se sente apto a vender, então você terá de fazer melhor, eu acho. Eu sei que, com algumas traduções, você se senta e, como faz com um conto, o traduz no seu computador, sozinho - mas canções são outra história, existem diferentes pessoas envolvidas, os acionistas e, claro, os intérpretes e os ouvintes.

Tenho um ótimo exemplo de uma canção alemã antiga sobre a mulher que tinha picadas de pulgas. Se você a cantar para uma plateia que não sabe alemão, eles não vão entender, não é? [Canta um trecho da canção em alemão] - parece ser alemão, mas isso é tudo! [risos]. [Citando de seu livro] “A noção de 'desvio não-obrigatório' exclui mudanças normais na ordem das palavras, ou outros procedimentos-padrão descritos em livrostexto e usados com frequência por bons tradutores, como a transposição e a modulação" (LOW, 2017, p. 116, tradução minha). Há um ótimo exemplo em inglês: você não traduz "village vert" como "village green", você traduz isso como "green village" - pois um "village green", na Inglaterra, é uma área gramada usada para a feira local ou para jogar críquete aos sábados - isso é

\footnotetext{
${ }^{17}$ Cf. Low (2017, p. 117).

18 “Na floresta, na floresta / Têm árvores / Têm árvores / Johnny viu um esquilo / Johnny viu um esquilo / E algumas abelhas / E algumas abelhas" (tradução literal minha, não cantável sobre a melodia original).
} 
o "village green". E, é claro, a ordem das palavras lhe informa - em inglês que a segunda delas é o substantivo, e a primeira é o adjetivo.

DC: Estamos chegando ao final da entrevista. $O$ senhor poderia nos dar um input sobre a evolução da tradução de canções desde que começou a pesquisar e a trabalhar nisso?

PL: Eu acho que, no caso dos romances e dos contos, a Teoria da Tradução melhorou a qualidade do que é publicado. Com a tradução de canções, eu ainda não vejo isso - na verdade, eu vejo uma confusão de adaptações, boas traduções e letras alternativas, que, afinal de contas, não são traduções.

DC: Que conselho o senhor daria para alguém que está se iniciando nas traduções cantáveis?

PL: Reconheça que algumas características da canção se perderão na tradução. Então, examine cuidadosamente o que o compositor estava fazendo nessa canção em particular, e identifique quais são as marcas mais relevantes, a fim de retê-las. Essa análise o ajudará a fazer as compensações necessárias de uma maneira ótima. E leia a página 109 do meu livro!

DC: Levando toda essa discussão em conta, o senhor gostaria de compor uma "coda" para a entrevista?

PL: Minha esperança é de que nós, os tradutores de canções, possamos cada vez mais enxergar nosso papel como aqueles que possibilitam às pessoas o acesso à produção artística em outras línguas e de outras culturas - e não (como tem acontecido) como pessoas que se apropriam, adaptam e exploram a criatividade alheia em benefício próprio. 


\section{Referências}

APTER, Ronnie; HERMAN, Mark. Translating for Singing: The Theory, Art and Craft of Translating Lyrics. London: Bloomsbury Academic, 2016.

KAISER, Andrea. Óperas no Brasil. Versões em português. 1999. 118 f. Dissertação (Mestrado em Musicologia) - Programa de Pós-Graduação em Artes. Escola de Comunicações e Artes. Universidade de São Paulo, São Paulo, SP, 1999.

LOW, Peter. Surtitles for Opera: A Specialised Task. Babel, Amsterdam, vol. 48, n. 2, p. 97-110, 2002.

LOW, Peter. Translating songs that rhyme. Perspectives: Studies in Translatology, London, vol. 16, n. 1-2, p. 1-20, 2008.

LOW, Peter. Translating Song: lyrics and texts. New York/London: Routledge, 2017.

NEWMARK, Peter. A Textbook of Translation. New York, Prentice Hall, 1988.

PARNY, Évariste. Selected Poetry and Prose of Évariste Parny. In English Translation, with French Text. Edited by Françoise Lionnet. Translated by Peter Low and Blake Smith. New York: The Modern Language Association of America, 2018. 